\title{
Prologue
}

\section{THE LIMITS OF FLEXIBILITY}

This catchphrase shown in figure $\mathrm{I}$, an advertisement created by the Talent agency in 1992 for the Brazilian consumer electronics firm Semp Toshiba, was "one of the most talked about ... in Brazilian advertising."1 It reflected a complex relationship between Brazil and Japan that was linked to the national identities of Brazil's one million citizens of Japanese descent. Connecting Brazil to Japan was not simply a marketing strategy: in popular language Nikkei (the term many Japanese-Brazilians use for themselves) are known simply as "japonês," because no linguistic distinction exists between Brazilians of Japanese descent and inhabitants of Japan itself. ${ }^{2}$ Rachel de Queiroz's short story "Nacionalidade" illustrates the point. Its young protagonist is called "japonês" by his friends, even though he constantly reminds them that he and his parents were born in Brazil. One child insists that "I never saw a person who was Brazilian and had a Japanese face. I thought that all Brazilians were the same." ${ }^{3}$ In the story race is a powerful metaphor for national identity and social hierarchy for Nikkei and for all Brazilians who are not "the same."

Relating ideas about Brazil and Japan to people of Japanese descent has a long history. It began in 1908, when the first of some 250,000 Japanese immigrants arrived. By I960 Brazil had the largest Nikkei population in the world. São Paulo was the world's largest "Japanese" city outside of Japan. 